\section{Effects of a short behavioural intervention for dental flossing: randomized-controlled trial on planning when, where and how}

\author{
Schüz B, Wiedemann AU, Mallach N, Scholz U. Effects of a short behavioural \\ intervention for dental flossing: randomized-controlled trial on planning when, where \\ and how.
}

\begin{abstract}
Aim: Regular dental flossing has been widely recommended to prevent periodontal diseases. Nevertheless, compliance is below a desirable level. This study evaluates the effects of a brief behavioural intervention on dental flossing and determines whether the effects of such an intervention are stronger in a specific subgroup of individuals (those intending to floss regularly = implemental mindset).

Materials and Method: Behavioural intervention (planning when, where and how to floss) trial was conducting with 194 participants assigned to an intervention or a control group by a random time schedule; the primary outcome was validated self-report of flossing behaviour. Follow-up data were collected 2 and 8 weeks post-intervention.

Results: Individuals receiving the planning intervention significantly outperformed those in the control condition at both the 2- and the 8-week follow-up (4.24 times flossing/week versus 3.9 at 2 weeks; 4.02 versus 2.98 at 8 weeks). Intervention effects were stronger in individuals in the implemental mindset. Dropout rates were higher for participants who received the planning intervention but were not in the implemental mindset.

Conclusion: Planning interventions are an economic and effective way to change oral self-care behaviour, and are more effective in individuals in an implemental mindset.
\end{abstract}

Benjamin Schüz' ${ }^{1}$, Amelie U. Wiedemann ${ }^{2}$, Natalie Mallach ${ }^{2}$ and Urte Scholz ${ }^{3}$

1 Deutsches Zentrum für Altersfragen (German Centre of Gerontology), Berlin, Germany; ${ }^{2}$ Freie Universität Berlin, Berlin, Germany; ${ }^{3}$ University of Zurich, Zurich, Switzerland
Recent years have witnessed great improvements in the treatment and prevention of periodontal diseases, and there seems to be a downward trend in prevalence (Hugoson \& Norderyd 2008).

\begin{tabular}{|c|}
\hline $\begin{array}{l}\text { Conflict of interest and source of } \\
\text { funding statement }\end{array}$ \\
\hline 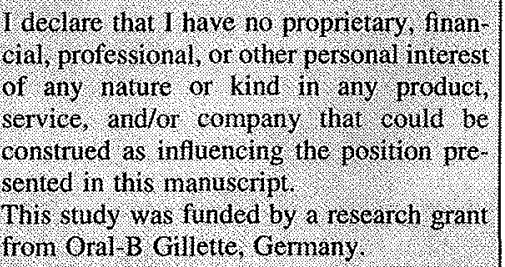 \\
\hline
\end{tabular}

However, according to the world oral health report (Petersen 2003), 30-60\% of the adult population still suffers from medium to severe periodontitis, depending on the region of assessment. In Germany, the prevalence of medium to severe periodontitis has even increased between 1997 and 2005 (Micheelis \& Schiffner 2006). Thus, measures to prevent periodontal disease need to remain on the agenda of preventive dentistry.

One key factor in preventing periodontal diseases is the regular use of dental floss or comparable inter dental hygiene measures in order to remove inter dental plaque (Brothwell et al
1998, Jackson et al. 2006, Corby et al. 2008). Accordingly, the regular, at best daily, use of inter dental hygiene measures has been recommended by major dental associations (ADA 2008, BDA n.d.). These recommendations underline that individual behaviour is the key factor for reaching prevention goals, because in order to be effective, floss needs to be applied on a continuous basis. In fact, all patient involvement in oral health is entirely behavioural (regular brushing, flossing, rinsing, keeping dentist appointments, etc.), and it has been argued that the understanding of the behavioural parameters 
in preventive dentistry is crucial for the control of oral diseases (Ciancio 2003, ten Cate 2004, Sniehotta et al. 2007).

However, despite increasing ease of use of inter dental cleaning devices, the acceptance and the regular use of such measures in the public remains rather low. For example, in Germany, the percapita use of dental floss adds up to only $2.2 \%$ of what could be expected from following the recommendations (Staehle 2004). In the European context, even in population subgroups with a relatively high socioeconomic status such as university students, only $9.2 \%$ (Schüz et al. 2006) or $15 \%$ (Rimondini et al. 2001) floss on a daily basis. Interventions to promote the maintenance of a regular oral health care regime have often failed to produce long-term effects. For example, in dental patients who have been motivated to use dental floss and who were instructed on how to use it, regular flossing decreased as soon as supervision ceased (Stewart \& Wolfe 1989).

In this context, health behaviour theories can offer insights and suggestions for behavioural interventions to enhance the initiation and maintenance of oral self-care behaviours such as dental flossing.

\section{Understanding oral self-care: behavioural theories}

Behavioural theories delineate the factors that are responsible for initiating and maintaining individual healthrelated behaviours. In the context of oral self-care, most studies have focused on theories such as the theory of planned behaviour (TPB; Ajzen 1991), which assume that an individual's intention for a behaviour is the crucial factor for changing it (McCaul et al. 1985, 1988, Tedesco et al. 1991, Rise et al. 1998, Syrjälä et al. 2002). According to these theories, people base their intentions to perform a specific behaviour mostly on their affective and cognitive expectations about the outcomes of the behaviour (attitudes), expectations about others' approval or disapproval of the behaviour (subjective norms) and their perceived behavioural control. Intentions and perceived behavioural control, in turn, are assumed to predict behaviour. Although such theories are widely applied to predict oral health behaviours, the evidence for the effectiveness of interventions for oral self-care based on these theories is weak (e.g. McCaul et al. 1992).
From the perspective of current behavioural theories, such results are not too surprising. Current behaviour change theories suggest to distinguish between at least two different mindsets of individuals during the process of behaviour change: A deliberative and an implemental mindset (e.g. Heckhausen \& Gollwitzer 1987). In the deliberative mindset, individuals contemplate about whether to act (e.g. to floss regularly), based on available information. After the formation of an intention, they enter the implemental mindset where the focus is entirely on translating this intention into action. Accordingly, the factors promoting intention formation are different from those promoting behaviour initiation and maintenance (Sheeran 2002). This differentiation might help explain why interventions focusing solely on education or determinants of motivation (i.e. intention formation) are not successful in the long run, as their primary focus is intention formation. According to mindset theory, forming intentions is a necessary but not sufficient precondition for changing behaviour. For the successful translation of intentions for oral self-care into behaviour, other factors are important.

There is evidence suggesting that planning in detail when, where and how to perform a behaviour is such a factor that helps translate intentions into action. These plans have proven effective to change a wide range of behaviours (Gollwitzer \& Sheeran 2006), and applications in the context of oral self-care behaviours also suggest that planning facilitates regular oral selfcare (Schüz et al. 2006, Sniehotta et al. 2007. Astrøm 2008, Wiedemann et al. 2009). Such plans are simple with regard to their structure: a precise description of a situation (when and where) is linked to a behavioural response (how). This structure then has to be encoded (e.g. by mental simulation: visualizing situation and response). As soon as the specified situation is encountered, the cognitive representations of the behavioural response for this situation are highly accessible, and behaviour enactment becomes more likely (Gollwitzer 1999). For example, a person who has made a plan such as "Every evening after brushing my teeth I will use dental floss in front of the mirror in my bathroom" will remember the behavioural response (floss in front of the mirror) with a high likelihood whenever the situation (every evening after brushing teeth) is encountered and act accordingly.

It has been shown that the effects of planning are particularly pronounced after intentions have been formed, because concrete plans can only serve the purpose of intentions and not substitute motivation to act in the first place (Gollwitzer 1996, Sheeran et al. 2005, Scholz et al. 2008, Wiedemann et al. in press). Thus, interventions based on planning should work better in individuals with an implemental mindset, because they are matched to this particular mindset.

Evidence for such differential effectiveness of interventions is crucial for the design and implementation of population-based oral public health interventions (Davies et al. 2005), because it would suggest to target different interventions at different groups of people. Additionally, the individual acceptance of interventions is an important parameter for cost-benefit analyses of interventions.

Previous studies on planning in the oral self-care context were inconclusive with regard to the differential effects of planning, or did not examine such differential effects on behaviour and in terms of acceptance. This study therefore is the first to evaluate the differential effectiveness of a planning intervention in individuals with deliberative or implemental mindsets. Moreover, this study aims at investigating the effects of planning on individual treatment acceptance as indicated by retention.

\section{Research questions}

This study aims at testing the effects of a short planning intervention on oral-self care behaviour, namely dental flossing. In a secondary set of analyses, it will be examined whether the effects of the intervention (both in terms of behaviour change and acceptance) are more pronounced in a specific subgroup of individuals, namely those in an implemental mindset.

\section{Materials and Method}

\section{Design}

The research questions were addressed in a randomized-controlled trial, with the primary outcome being measured at baseline, 2 and 8 weeks post-intervention. 


\section{Participants and procedure}

Participants were a convenience sample drawn at an open day at Freie Universität Berlin, Germany (see Fig. 1 for participant flow through the study). Inclusion criteria were being over 18 years of age (full age) and speaking sufficient German to answer the questionnaire. The study was conducted in full accordance with the declaration of Helsinki (WMA 2004). In order to detect medium-size effects (Cohen's $d=0.5$ ), as can be expected for planning interventions (Gollwitzer \& Sheeran $2006)$ with a power of $0.80(\alpha=0.05)$, a sample size of at least 51 individuals/ group was determined using the software $G^{*}$ Power 3 (Faul et al. 2007). A 2:1 oversampling of the planning condition was used due to suggestions of the organizing committee of the open day - they preferred having more people participating in an intervention than being in the control group.

Trained graduate psychology students approached about 250 individuals, of whom $N=194$ agreed to participate. Because of time and location constraints, no systematic analysis of refusals was possible. Recruitment over and above the sample size required (194 compared with 153) was based on a retention estimate of $80 \%$ of participants. The sample $(N=194)$ comprised of $68.1 \%$ women, and was on average 33.59 years of age $(\mathrm{SD}=13.54$; range $18-71)$. Education was comparably high, with $41.2 \%$ having college degrees and $38.2 \%$ having completed university education.

The baseline questionnaire assessed dental flossing behaviour and mindset. Participants filled in the questionnaire on site and returned it to the interviewers. The time 1 questionnaire ( 2 weeks after baseline) assessed dental flossing frequency and socioeconomic data and the time 2 questionnaire ( 8 weeks after baseline) assessed dental flossing behaviour. Both time 1 and time 2 were mailed to participants together with a prepaid return envelope. The time 1 mailing additionally included another sample of dental floss. Nonrespondents at time 1 and time 2 (i.e. not responding after 2 weeks) received one reminder phone call (Fig. 1).

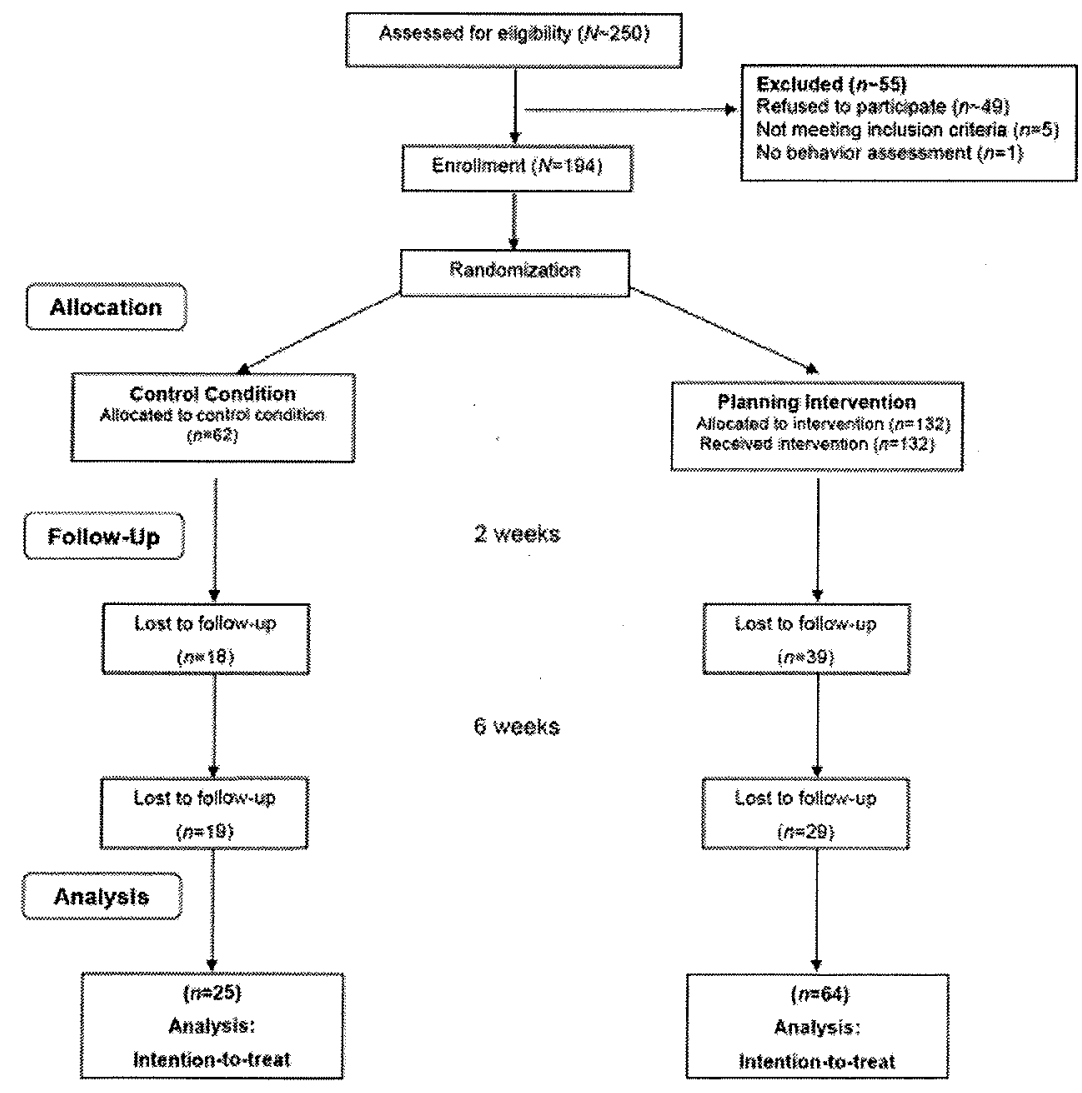

Fig. l. Study flowchart.

\section{Mode of delivery}

Participants were approached and interviewed by trained graduate students. All study material, except for the flossing samples, was branded with university logos in order to avoid the impression of a commercial advertising campaign. After giving informed consent, participants received dental floss (Oral-B satin floss, $5 \mathrm{~m}$ samples, Procter \& Gamble, Gillette, Schwalbach, Germany) as well as a postcard based on ADA (2008) flossing information (improved hygiene, effective prevention of oral diseases), together with flossing instructions, and filled in the questionnaire. Participants in the planning condition additionally received the planning intervention.

\section{Planning intervention}

Participants in the planning condition received a 3 -min. one-to-one planning intervention adapted from Sniehotta et al. (2005) delivered by trained graduate students. Participants were read the statement "You are more likely to regularly clean between your teeth if you make an exact plan when, where, and how you will do so. Please write down your plan in the table below. The more precise and personal you formulate your plan, the more it will help you'". The table contained columns entitled "When?", "Where?", "With what?" and "How often per week?" After filling in their plans, participants were asked to visually imagine themselves in the situations specified in their plans to enhance encoding of the plan. Participants were invited to ask the interviewers in cases of misunderstandings or other questions.

\section{Randomization procedure}

Participants were allocated to the intervention or the control group according to a time schedule with randomly generated shifts using a web-based randomizer (Urbaniak \& Plous 2008). Interviewers changed experimental conditions every $30 \mathrm{~min}$. over the open day according to this schedule (e.g. from 10:00 to $10: 30$ hours, all participants received the planning intervention, from 10:30 to 11:00 hours, all participants were allocated to the control condition, etc.). Interviewers were not blind to the experimental conditions, as they had to deliver the intervention. 


\section{Measures}

The primary study outcome was a validated 7-day recall of dental flossing: "How often did you use dental floss during the last seven days?" Participants who had not used dental floss in the last 7 days were asked how often they used floss during the last month. The measure was adopted from previous research and has been validated against a measure of residual dental floss (McCaul et al. 1985, Schuiz et al. 2007, Sniehotta et al. 2007). The secondary outcome of the study, acceptance, was assessed by the proxy measure of remaining in the study at time 2 , as there are high correlations between non-acceptance or non-satisfaction and attrition (Sears \& Stanton 2001).

Mindsets were assessed using a validated algorithm for dental flossing (adapted from Schïz et al. 2007). After the question "Are you currently using dental floss?", participants answering "no" were asked to choose one of the following alternatives: (i) "I know what to use dental floss for", (ii) "I have thought about using dental floss" or (iii) "I have the intention to use dental floss". Participants answering "yes" were asked to choose one of the following alternatives: (iv) "I don't use dental floss as often as intended" (v) "I use dental floss as often as intended" or (vi) "Flossing is habitual to me and requires no effort at all". According to the mindset theory, participants answering items (i) or (ii) were classified as being in the deliberative mindset, and participants answering items (iii) to (vi) were classified as being in the implemental mindset.

\section{Statistical analyses}

Intervention effects on flossing behaviour were evaluated using analysis of covariance (ANCOVA) at both time 1 and time 2 with intervention and mindset as between-subjects factors and controlling for baseline levels of dental flossing as a covariate. We conducted intent-to-treat analyses by analysing the last available observation of every participant as the primary outcome at time 1 and time 2 (Last Observation Carried Forward; Houck et al. 2004). This means that e.g., for participants dropping out after baseline, these last available observations were imputed for the time 1 and time 2 analyses. This type of intent-totreat analysis produces a rather conser- vative estimation of behaviour. Dropout analysis to investigate differences in available measures between those in the longitudinal sample and those dropping out was conducted using logistic regression. Randomization checks were conducted using ANOVA. Intervention acceptance was analysed by logistic regression. All analyses were run using SPSS 15 for Windows.

\section{Resuits}

\section{Mindsets}

At baseline, 137 participants were classified as being in the deliberative mindset (of which 95 received the intervention), and 57 classified as being in the implemental mindset (of which 37 received the intervention). Implemental mindset participants used dental floss significantly more often than deliberative mindset participants at baseline (4.34 times compared with 0.71 times, $t=$ $-8.66, \mathrm{df}=83, p<0.01$ ).

\section{Dropout analyses}

Overall, 57 individuals dropped out between baseline and time 1 (see Fig. 1). Logistic regression analysis was used to predict continuation in the study from baseline flossing, baseline mindset and intervention group. None of these factors significantly predicted dropout. Between baseline and time 2, a total of 104 participants dropped out. Again, logistic regression analysis with baseline flossing, baseline mindset and the intervention group revealed no significant predictors of study discontinuation, indicating that dropout at both follow-up measurements was not due to baseline differences in the behaviour, mindset or experimental group.

\section{Randomisation checks}

A univariate analysis of variance with experimental group as the factor and baseline flossing frequency as the dependent variable was conducted to test whether the randomization procedure was successful $(F(1,193)=1.65$, $p=0.20$ ), indicating that the experimental groups did not differ with regard to the baseline flossing frequency. Similarly, experimental groups did not differ with regard to mindsets $\left(\chi^{2}=3.81\right.$, $\mathrm{df}=6, p=0.70$ ).

\section{Effects of the intervention on behaviour}

The means and standard deviations of dental flossing frequency across time, mindsets and groups are depicted in Table 1; the summary of the ANCOVA is presented in Table 2 .

The overall mean flossing frequency/ week increased from 1.99 at baseline to 4.19 at time 1 and 4.32 at time 2. This speaks in favour of providing participants with floss and flossing instructions in order to promote flossing. At both time 1 and time 2 , the effect of the intervention was significant. At time 1, participants in the intervention group flossed on average 4.24 times/week, compared with 3.90 times/week for

Table 1. Adjusted means (controlled for baseline) and standard errors (SE) for dental flossing/ week across intervention groups and mindsets for baseline (non-adjusted) and follow-ups

\begin{tabular}{|c|c|c|c|c|c|}
\hline Intervention group & Mindset & Time & Mean & SE & $95 \% \mathrm{CI}$ \\
\hline \multirow[t]{9}{*}{ Control } & \multirow[t]{3}{*}{ Deliberative $(n=42)$} & Baseline & 0.92 & 0.29 & $0.35-1.48$ \\
\hline & & 1 & 2.43 & 0.51 & $1.44-3.43$ \\
\hline & & 2 & 2.22 & 0.47 & $1.30-3.15$ \\
\hline & \multirow{3}{*}{ Implemental $(n=20)$} & Baseline & 4.88 & 0.42 & $4.06-5.69$ \\
\hline & & 1 & 3.75 & 0.81 & $2.15-5.35$ \\
\hline & & 2 & 3.74 & 0.75 & $2.25-5.23$ \\
\hline & \multirow[t]{3}{*}{ Overall $(n=62)$} & Baseline & 2.89 & 0.25 & $2.40-3.40$ \\
\hline & & 1 & 3.90 & 0.46 & $2.20-3.99$ \\
\hline & & 2 & 2.98 & 0.42 & $2.15-3.82$ \\
\hline \multirow[t]{9}{*}{ Planning } & \multirow[t]{3}{*}{ Deliberative $(n=95)$} & Baseline & 0.68 & 0.19 & $0.31-1.06$ \\
\hline & & 1 & 2.90 & 0.36 & $2.20-3.60$ \\
\hline & & 2 & 2.75 & 0.33 & $2.09-3.40$ \\
\hline & \multirow[t]{3}{*}{ Implemental $(n=32)$} & Baseline & 3.99 & 0.31 & $3.38-4.59$ \\
\hline & & 1 & 5.57 & 0.59 & $4.40-6.74$ \\
\hline & & 2 & 5.30 & 0.55 & $4.21-6.38$ \\
\hline & \multirow[t]{3}{*}{ Overall $(n=132)$} & Baseline & 2.34 & 0.18 & $1.98-2.69$ \\
\hline & & 1 & 4.24 & 0.32 & $3.61-4.86$ \\
\hline & & 2 & 4.02 & 0.29 & 3.444 .60 \\
\hline
\end{tabular}

$\mathrm{Cl}$, confidence interval. 
Table 2. Summary of analysis of covariance at time 1 and time 2

\begin{tabular}{|c|c|c|c|c|}
\hline Source & df & MS & $F$ & $\eta^{2}$ \\
\hline \multicolumn{5}{|l|}{ Time 1} \\
\hline $\begin{array}{l}\text { Baseline flossing } \\
\text { (covariate) }\end{array}$ & 1 & 268.96 & $26.38^{* *}$ & 0.12 \\
\hline Intervention & 1 & 46.16 & $4.53^{*}$ & 0.03 \\
\hline Mindset & 1 & 82.89 & $8.13^{* * *}$ & 0.04 \\
\hline $\begin{array}{l}\text { Intervention } \times \\
\text { mindset }\end{array}$ & 1 & 16.22 & 1.59 & 0.01 \\
\hline \multicolumn{5}{|l|}{ Time 2} \\
\hline $\begin{array}{l}\text { Baseline flossing } \\
\text { (covariate) }\end{array}$ & 1 & 307.67 & $34.89^{* *}$ & 0.16 \\
\hline Intervention & 1. & 38.22 & $4.34^{*}$ & 0.02 \\
\hline Mindset & 1 & 86.29 & $9.79^{* *}$ & 0.05 \\
\hline $\begin{array}{l}\text { Intervention } \times \\
\text { mindset }\end{array}$ & 1 & 9.50 & 1.08 & 0.01 \\
\hline
\end{tabular}

those in the control group. This difference increased at time 2; here, participants in the planning group flossed on average 4.02 times/week, whereas those in the control group fell back to baseline levels with 2.98 times flossing/week. Figure 2 shows the mean differences at time 2.

At both time points, the intervention $\times$ mindset term was not significant. Pairwise comparisons of the groups, however, revealed that implemental mindset participants receiving the planning intervention flossed significantly more often at time $2(M=5.30)$ than implemental mindset participants in the control group $(M=3.74)$, and deliberative mindset participants in both the planning. $(M=2.75)$ and the control $(M=2.22)$ group (all $p s<0.05)$. The mean differences between implemental mindset individuals in the planning group and implemental mindset participants in the control group represent a small effect size $(d=0.22)$. The difference between implemental and deliberative participants in the planning group represents a large effect size $(d=1.19)$. Finally, the mean difference between individuals with an implemental mindset in the planning condition and deliberative participants in the control group also indicated a large effect size $(d=1.32)$.

\section{Intervention acceptance}

The second aim of this study was to test for differences in acceptance (retention) of the treatment with regard to the mindset of participants. While the primary dropout analysis does not suggest main effects of the study variables on attrition, a secondary logistic regression analysis including the interaction term mindset $x$ intervention was conducted. The results of this analysis suggest that deliberative individuals who receive the planning intervention were more likely to dropout (see Fig. 3; odds ratio $=0.26$, $p<0.05,95 \%$ confidence interval $=$ $0.07-0.97$ ). Thus, acceptance of the planning intervention seemed to be higher in individuals with an implemental mindset.

\section{Discussion}

This study aimed at testing the effects of a short behavioural intervention on dental flossing, and whether such a planning intervention works and is accepted differentially in individuals in different mindsets (Heckhausen \& Gollwitzer 1987). Encouraging individuals to form a detailed plan about when, where and how they were going to floss signifi- cantly improved dental flossing performance at both a 2- and an 8-week follow-up as compared with a control group receiving only dental flossing instructions and dental floss samples. This replicates recent work on the effects of planning interventions for dental flossing (Sniehotta et al. 2007). Our study adds to this evidence in that the effects of such a planning intervention are stronger in individuals with an implemental mindset, i.e., who have already formed a behavioural intention to floss. Moreover, our results reveal that acceptance of the intervention is lower in deliberative mindset individuals as they are more likely to dropout of the study.

The significant effects of the planning intervention on dental flossing at both time 1 and time 2 correspond with a large body of evidence from other behaviours (Gollwitzer \& Sheeran 2006), which suggests medium to large effects of planning on behaviour change. Reg-

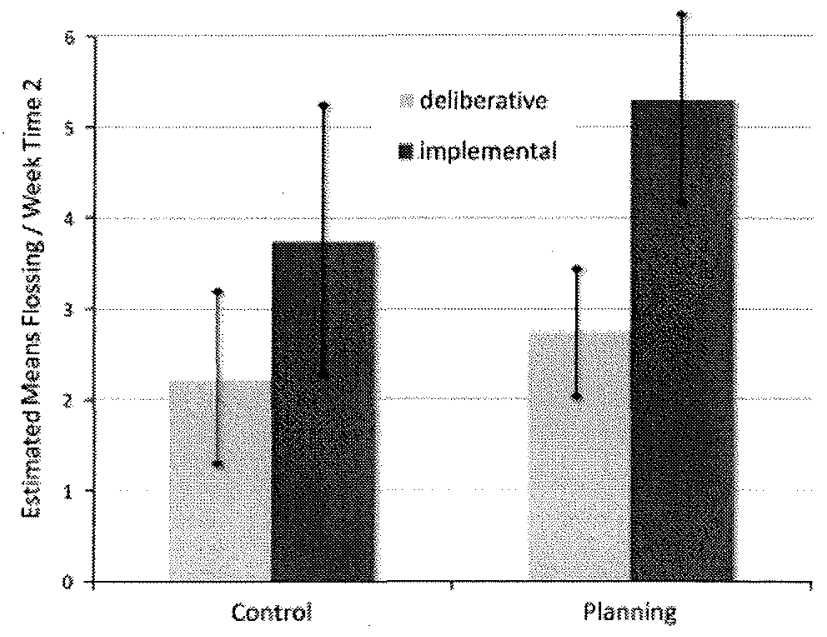

Fig. 2. Estimated marginal means of dental flossing frequency at time 2 across intervention groups and mindsets with $95 \%$ confidence intervals.

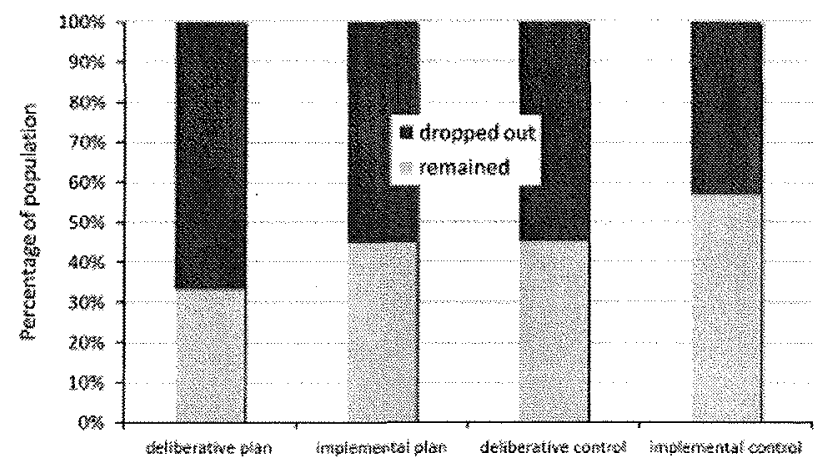

Fig. 3. Attrition at time 2 broken down by mindset and intervention group (percentage remaining and dropped out in respective populations). 
arding the present study, it seems noteworthy that while the overall difference in flossing between the intervention and the control group is relatively smal at time 1 ( 0.34 times flossing/week; Cohen's $d=0.11$ ), this difference increases by time 2 (1.04 times floss. ing/week; Cohen's $d=0.28$ ), which is mainly due to individuals in the control group recessing to baseline levels of flossing, while individuals in the planning group retained higher levels of flossing. This finding points to the potential long-term effects of such behavioural interventions on oral self-care behaviour. All participants received dental floss instructions and samples at baseline, which might account for the general increase in dental flossing levels in both groups between baseline and 2-week follow-up. Only in the planning group, however, were these increased levels maintained over the whole study period. This speaks in favour of supplementing dental health education and skill-building interventions (Hugoson et al. 2007) with self-generated specific plans on when, where and how to act (Gollwitzer 1999, Schüz et al. 2006).

The finding that the effects of the planning intervention were particularly pronounced in individuals with an implemental mindset, i.e., those who already formed an intention to floss, supports the basic idea of the mindset theory (Heckhausen \& Gollwitzer 1987), namely that there are different processes involved in goal setting and goal pursuit. Formulating plans about when, where and how to floss facilitates change in flossing only if participants actually intend to do so. If participants hold no intention, prompting them to form plans will not facilitate behaviour change and could even lead to reactance. In fact, a secondary analysis confirmed that participants in the deliberative mindset (no intentions to floss) receiving the planning intervention were more likely to drop out of the study. This is an important finding for the implementation of behavioural interventions in dental practice, because it suggests that such interventions are effective if targeted at individuals in an implemental mindset, but may result in reactance or disinterest if targeted at individuals in a deliberative mindset. Previous work on differential effects of self-monitoring for dental flossing (Schüz et al. 2007) further underscores the idea of different mindsets in individuals. In undecided participants, other strategies to promote the contemplation process besides planning might be more effective, e.g. providing information about the symptoms, causes, consequences, temporal course and contro measures for periodontal disease (Philippot et al. 2005). Additionally, tailoring interventions to individuals' approach versus avoidance orientation has shown considerable effects on oral hygiene behaviour (Sherman et al. 2008).

There are some limitations to our study. First, the attrition rate was relatively high and exceeded retention estimates. Therefore, intent-to-treat analyses were conducted controlling for dropout by analysing the last available measure ment of each individual. The high attrition might be due to the fact that the sample was collected at a university open day and that motivation to partici pate in an unpaid, longitudinal study might be lower than in other samples such as students receiving course credits. There was no attention control for the control group; thus, the possibility that treatment effects are solely due to prolonged contact with the interviewers cannot entirely be ruled out, even though the contact duration was not $>5$ min. Because of time and location constraints, the study relied on assessing changes in flossing behaviour only, which does not necessarily correspond with changes in periodontal status. Further studies should include measures of periodontal status in order to evaluate the clinical effectiveness of behavioural interventions (e.g. Philippot et al. 2005). Furthermore, our primary outcome measure was self-reported. However, previous studies have demonstrated the high validity of such 7-day recalls (McCaul et al. 1985, Schüz et al, 2006, Sniehotta et al. 2007). In spite of the satisfactory validity, the less than perfect congruence between self-reports and behaviour might mask differential dropout: participants dropping out of the study might have lower congruence between self-reports and actual behaviour and thus floss less than those remaining in the study, even if the dropout analyses suggested no differences in self-reported flossing. [We thank an anonymous reviewer for pointing this out: some studies have shown a differential validity of selfreports in subgroups, but the direction of differential validity is unclear (there is both over-reporting and under-reporting in risk groups, see, e.g., Murphy et al. 2000; but see also Field et al. 2007).]
The secondary outcome, acceptance, was defined as remaining in the study. This definition might fall short of assessing individual reasons for dropout and does not include process measures of treatment satisfaction and acceptance. However, as non-acceptance of and low satisfaction with treatments is highly indicative of attrition (e.g. Sears \& Stanton 2001), we chose retention as an economic proxy assessment of acceptance. The assessment of mindset was based on a single-item measure, which might be accompanied by limitations in reliability. However, single-item measures of mindsets are well established, and it has been discussed that mutually exclusive categories in single items are better suited to assess different mindsets than scales with continuous measures (e.g. Herzog 2008). Such single-item measures perform satisfactorily with regard to specificity and sensitivity (Lippke et al. 2009). The mindset item was phrased in terms of dental flossing. It is possible that individuals using other inter-dental cleaning devices such as inter-dental brushes were classified incorrectly as "deliberative" using the current item, although they might be using brushes on a regular basis. The finding that the deliberative sample engaged in at least some inter-dental hygiene $(0.71 /$ week) indicates that there might be individuals using other devices in this sample. However, as the prevalence of inter-dental brushing in Germany is very low with an average usage of 0.4 brushes per capita and year (Staehle 2004), we refrained from assessing inter-dental brushing in the questionnaire. The study sample was well educated, and health behaviours, especially dental flossing, commonly correlate with education (Rimondini et al. 2001). Therefore, this sample cannot be considered representative for the general population. However, with initial levels of 2.62 times flossing/week, this sample also performs well below the recommendations of daily flossing. Additionally, while previous research was mainly based on student samples, this study included more individuals from the general population.

This demonstrates the potential for replications of this study in other populations, e.g. periodontal risk patients Future studies might also wish to increase the intervals between assessments in order to examine further longterm effects of behavioural interventions. 
Nevertheless, the three main findings from this study - that a planning intervention produces sustaining changes in dental flossing frequency, that this intervention is most effective in participants in the implemental mindset and that participants in the deliberative mindset receiving an intervention mismatched to their mindset are more likely to reject such an intervention (discontinue participation) might have some practical implications: Formulating plans constitutes an economic and effective intervention to facilitate oral self-care, which can easily be implemented in practical settings. In the dental context, for example, dentists or dental hygienists could implement such plans in the dental hygiene treatment and ask implemental patients to form such plans at the end of the session, after they have received flossing instructions.

\section{Acknowledgements}

The authors would like to thank Monika Berus, Melanie Conradt, Franziska Heimrich and Nadja Matysiak for their assistance with data collection.

\section{References}

ADA. (2008) Cleaning your teeth and gums (oral hygiene). Available at http:/www.ada. org/public/topics/cleaning_faq.asp\#4 (accessed on 14 October 2008).

Ajzen, I. (1991) The theory of planned behavior. Organizational Behavior and Human Decision Processes 50, 179-211.

Astrøm, A. N. (2008) Applicability of action planning and coping planning to dental flossing among Norwegian adults: a confirmatory factor analysis approach. European Journal of Oral Science 116, 250-259.

BDA. (n.d.). Flossing. Available at http:// www.bdasmile.org/adults/adults.cfm?conten tid $=12678$ contentparentid $=1036$ (accessed on 14 October 2008).

Brothwell, D. J., Jutai, D. K. \& Hawkins, R. J. (1998) An update of mechanical oral hygiene practices: evidence-based recommendations for disease prevention. Journal of Canadian Dental Association 64, 295-306.

Ciancio, S. (2003) Improving oral health: current considerations. Journal of Clinical Periodontology 30, 4-6

Corby, P. M., Biesbrock, A., Bartizek, R. Corby, A. L., Monteverde, R., Ceschin, R. \& Bretz, W. A. (2008) Treatment outcomes of dental flossing in twins: molecular analysis of the interproximal microflora. Joumal of Periodontology 79, 1426-1433.

Davies, I., Karring, T. \& Norderyd, O. (2005) Advances in the behavioural and public health aspects of periodontitis. Group $E$ consensus report of the fifth European Workshop in Periodontology. Journal of Clinical Perio dontology 32 (Suppl. 6), 326-327.

Faul, F., Erdfelder, E., Lang, A.-G. \& Buchner A. (2007) $\mathrm{G}^{*}$ Power 3: a flexible statistica power analysis for the social, behavioral, and biomedical sciences. Behavior Research Methods 39, 175-191.

Field, A. E., Aneja, P. \& Rosner, B. (2007) The validity of self-reported weight changes among adolescents and young adults. Obesity 15, 2357-2364.

Gollwitzer, P. M. (1996) The volitional benefits of planning. In: Gollwitzer, P. M. \& Bargh, J. A. (eds). The Psychology of Action: Linking Cognition and Motivation to Behavior, pp. 287-312. New York: Guilford.

Gollwitzer, P. M. (1999) Implementation intentions: strong effects of simple plans. American Psychologist 54, 493-503.

Gollwitzer, P. M. \& Sheeran, P. (2006) Implementation intentions and goal achievement: a meta-analysis of effects and processes. In: Advances in Experimental Social Psychology 38, 69-119.

Heckhausen, H. \& Gollwitzer, P. M. (1987) Thought contents and cognitive functioning in motivational versus volitional states of mind. Motivation and Emotion 11, 101-120.

Herzog, T. (2008) Analyzing the transtheoretical model using the framework of Weinstein, Rothman, and Sutton (1998): the example of smoking cessation. Health Psychology 27, 548-556.

Houck, P. R., Mazumdar, S., Koru-Sengul, T., Tang, G., Mulsant, B. H., Pollock, B. G. \& Reynolds, C. F. III (2004) Estimating treatment effects from longitudinal clinical trial data with missing values: comparative analyses using different methods. Psychiatry Research 129, 209-215.

Hugoson, A., Lundgren, D., Asklöw, B. \& Borgklint, G. (2007) Effect of three different dental health preventive programmes on young adult individuals: a randomized, blinded, parallel group, controlled evaluation of oral hygiene behaviour on plaque and gingivitis. Journal of Clinical Periodontology $34,407-415$

Hugoson, A. \& Norderyd, O. (2008) Has the prevalence of periodontitis changed during the last 30 years? Joumal of Clinical Periodontology 35, 338-345.

Jackson, M. A., Kellett, M., Worthington, H. V \& Clerehugh, V. (2006) Comparison of interdental cleaning methods: a randomized controlled trial. Journal of Periodontology 77 1421-1429.

Lippke, S., Ziegelmann, J. P., Schwarzer, R. \& Velicer, W. F. (2009) Validity of stage assessment in the adoption and maintenance of physical activity and fruit and vegetable consumption. Health Psychology 28, 183 193.

McCauI, K. D., Glasgow, R. E. \& Gustafson, C. (1985) Predicting levels of preventive denta behaviors. Journal of the American Dental Association 111, 601-605.

McCaul, K. D., Glasgow, R. E. \& O'Neill, H. K. (1992) The problem of creating habits: estab- lishing health-protective dental behaviors. Health Psychology 11, 101-110.

McCaul, K. D., O'Neill, H. K. \& Glasgow, R. E. (1988) Predicting the performance of dental hygiene behaviors: an examination of the Fishbein and Ajzen model and self-efficacy expectations. Journal of Applied Social Psychology 18, 114-128.

Micheelis, W. \& Schiffner, U. (2006) Vierte Deutsche Mundgesundheitsstudie (DMS IV): Neue Ergebnisse zu oralen Erkrankungsprävalenzen, Risikogruppen und zum zahnärzllichen Versorgungsgrad in Deutschland 2005. Köln: Deutscher Zahnärzte Verlag.

Murphy, D. A., Durako, S., Muenz, L. R. \& Wilson, C. M. (2000) Marijuana use among HIV-positive and high-risk adolescents: a comparison of self-report through audio computer-assisted self-administered interviewing and urinalysis. American Journal of Epidemiology 152, 805-813.

Petersen, P. E. (2003) The World Oral Health Report 2003: continuous improvenent of oral health in the 21 st century - the approach of the WHO Global Oral Health Programme. Community Dentistry and Oral Epidemiology 31 (Suppl. 1), 3-23.

Philippot, P., Lenoir, N., Hoore, W. \& Bercy, P. (2005) Improving patients' compliance with the treatment of periodontitis: a controlled study of behavioural intervention. Journal of Clinical Periodontology 32, 653-658.

Rimondini, L., Zolfanelli, B., Bernardi, F. \& Bez, C. (2001) Self-preventive oral behavior in an Italian university student population. Journal of Clinical Periodontology 28, 207. 211

Rise, J., Astrøm, A. \& Sutton, S. (1998) Predicting intentions and use of dental floss among adolescents: an application of the theory of planned behaviour. Psychology and Health 13, 223-236.

Scholz, U., Schüz, B., Ziegelmann, J. P., Lippke, S. \& Schwarzer, R. (2008) Beyond behavioural intentions: planning mediates between intentions and physical activity. British Journal of Health Psychology 13, 479-494.

Schüz, B., Sniehotta, F. F. \& Schwarzer, R. (2007) Stage-specific effects of an action control intervention on dental fossing. Health Education Research 22, 332-341.

Schüz, B., Sniehotta, F, F., Wiedemann, A. \& Seemann, R. (2006) Adherence to a daily flossing regimen in university students: effects of planning when, where, how and what to do in the face of barriers. Journal of Clinical Periodontology 33, 612-619.

Sears, S. R. \& Stanton, A. L. (2001) Expectancy-value constructs and expectancy violation as predictors of exercise adherence in previously sedentary women. Health Psychology 20, 326-333.

Sheeran, P. (2002) Intention-behaviour relations: a conceptual and empirical review. In: Hewstone, M. \& Stroebe, W. (eds). European Review of Social Psychology, Vol. 12, pp. 136. New York: Wiley.

Sheeran, P., Webb, T. L. \& Gollwitzer, P. M. (2005) The interplay between goal intentions 
and implementation intentions. Personality and Social Psychology Bulletin 31, 87-98.

Sherman, D. K., Updegraff, J. A. \& Mann, T. (2008) Improving Oral Health Behavior. Journal of the American Dental Association 139, 1382-1387.

Sniehotta, F. F., Scholz, U., Schwarzer, R. Behr, H., Fuhrmann, B., Kiwus, U. \& Völler, H. (2005) Long-term effects of two psychological interventions on physical exercise and self-regulation after coronary rehabilitation. International Joumal of Behavioral Medicine 12, 244-255.

Sniehotta, F. F., Soares, V. A. \& Dombrowski S. U. (2007) Randomised controlled trial of a one-minute intervention changing oral selfcare behaviour. Journal of Dental Research $86,641-645$.

Staehle, H. J. (2004) Das aktive Mundgesundheitsverhalten in Deutschland und in der Schweiz [Active oral health behavior in Germany and Switzerland]. Schweizerische Monatsschrift Zahnmedizin 114, 1236-1251.

\section{Clinical Relevance}

Sctentific rationale for the study: Regular fiossing is widely recom mended. but adherence to recommendations is unsatisfactory. This study evaluated the effects of a brief behavioural intervention (planning when, where and how to use floss)
Stewart, J. E. \& Wolfe, G. R. (1989) The retention of newly-acquired brushing and flossing skills. Journal of Clinical Periodontology 16, 331-332.

Syrjälä, A. M., Niskanen, M. C. \& Knuuttila, M. L. (2002) The theory of reasoned action in describing tooth brushing, dental caries and diabetes adherence among diabetic patients. Journal of Clinical Periodontology 29, 427 432.

Tedesco, L. A., Keffer, M. A. \& Fleck-Kandath, C. (1991) Self-efficacy, reasoned action, and oral health behavior reports: a social cognitive approach to compliance. Journal of Behavioral Medicine 14, 341-355.

ten Cate, J. M. (2004) Fluoride in caries prevention and control: empiricism or science. Caries Research 38, 254-257.

Urbaniak, G. C. \& Plous, S. (2008) Research Randomizer. Available at http://www.rando mizer.org/ (accessed on 8 October 2008).

Wiedemann, A. U., Schiz, B., Sniehotta, F. F. \& Schwarzer, R. (2009) Disentangling the

Address:

Benjamin Schüz

Deutsches Zentrum für Altersfragen (German

Centre of Gerontology)

Manfred-von-Richthofen-Str. 2

12101 Berlin

Germany

E-mail: benjamin.schuez@dza.de

and tested the differential effective ness of the intervention in specific sulbgroups

Princhal findings: Participants recelving the planning intervention outperformed controls at both a 2 and an 8 week follow up. Participants who intended to floss profited most from the planning intervention

Practical implications: Planning is an economis strategy for individual behaviour change that can be imple. mented in the dental practice. Stronger effects might be expected in participants with intentions. 